SPECIAL

BIBLIOGRAPHY

SERIES

NO. 84

\title{
A REVOLUTIONARY WAR: KOREA AND THE TRANSFORMATION OF THE POSTWAR WORLD
}

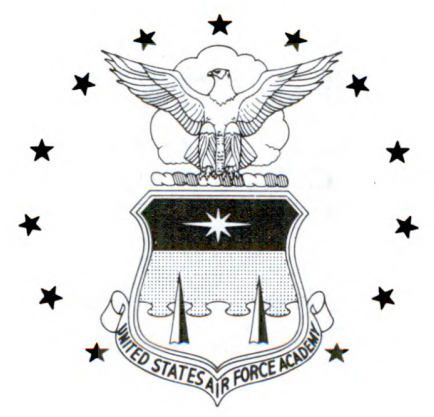

OCTOBER 1992 